G127(P) SNAP AND SHARE - A NOVEL APPROACH TO MEDICAL EDUCATION

${ }^{1} \mathrm{~N}$ Keren, ${ }^{1} \mathrm{C}$ Stenson, ${ }^{2} \mathrm{E}$ Loucaides, ${ }^{1} \mathrm{~S}$ Gabbie. ${ }^{1}$ Paediatrics, Royal Free Hospital NHS FT, London, UK; ${ }^{2}$ Paediatrics, University College London NHS FT, London, UK

10.1136/archdischild-2020-rcpch.100

Background Junior doctors rotate between difference specialties to gain a breadth of experience but may have little experience in the specialty they are working in and therefore feel less confident and may present a risk to patient safety. Innovative ways of maximising learning from teaching opportunities are needed to improve knowledge and confidence.

Aims

- Increase confidence of junior doctors in managing common paediatric problems

- Maximise learning from each teaching opportunity and share with as many juniors as possible

Methods During their general paediatrics rotation, junior doctors have three morning teaching sessions a week; simulation, consultant-led and case-based discussions. We introduced a 'snap and share' proforma to summarise key learning points and further resources from each morning teaching session. They were photographed and shared on the junior doctors' WhatsApp group.

Results Trainees reported a mean 40\% increase in knowledge and confidence of the topic after receiving the 'snap and share' material.

Conclusion

- The 'snap and share' model is effective for engaging trainees in learning and improving confidence in topic material

- Sharing learning in this way maximisers learning opportunities in paediatric trainees in this department

\section{G128(P) 'ASSESSMENT TO TREAT RATHER THAN ADMISSION TO ASSESS': ESTABLISHING A PERMANENT PAEDIATRIC ASSESSMENT UNIT AT A DISTRICT GENERAL HOSPITAL}

${ }^{1} \mathrm{G}$ Modgil, ${ }^{1} \mathrm{~A}$ Whiting, 'S Pilkington, ${ }^{1} \mathrm{C}$ Jackson, ${ }^{2} \mathrm{H}$ Peters, ${ }^{2} \mathrm{M}$ Bryant, ${ }^{2} \mathrm{R}$ Baum, ${ }^{3}$ A Knight. ${ }^{1}$ Paediatric Department, Taunton and Somerset NHS Foundation Trust, Taunton, UK; ${ }^{2}$ Executive Team, Taunton and Somerset NHS Trust, Taunton, UK; ${ }^{3}$ Management Team, Taunton and Somerset NHS Trust, Taunton, UK

\subsection{6/archdischild-2020-rcpch.101}

Aim A quality improvement Paediatric Assessment Unit (PAU) pilot creating a consistent model of 'assessment to treat' rather than 'admission to assess'. To establish a permanent PAU at a district general hospital (DGH). Specific aims included improving quality of care, reducing unnecessary admissions, improving patient experience, increasing primary care access to senior advice and bringing paediatrics services in line with an 'integrated front door' approach.

Method Historically, paediatric assessments and admissions had the same care pathway at our DGH. Local CCG analysis indicated that children were twice as likely to be admitted compared to other regional units with separate PAU facilities. A funded 3 month pilot PAU ran from January- April 2019. The pilot ensured that senior decision making took place at the point of referral, triage and review.

Results 434 children attended during this time. Of these, 122 children were assessed and subsequently admitted (28\%) and
312 were treated and allowed home (72\%). Proportion of patients waiting to receive a clinical decision greater than 120 minutes fell from $46 \%$ to $10 \%$, with significantly more children receiving a clinical decision within 60 minutes, exceeding RCPCH standards. Improved advice to primary care: $31 \%$ calls given specialist advice, decreasing admission/ referrals to outpatients. Consultant Connect answer rates increased from $54 \%$ to $83 \%$, with $56 \%$ patients avoiding an unnecessary visit to hospital. 100\% children screened for sepsis with significant improvements for children requiring antibiotics within one hour. There were less reported patient/ carer concerns with positive patient experience. Staff experience was universally positive with improved working environment, structure and morale. Trainee exception reporting reduced. GMC Trainee Survey results improved by two quartile positive shift for workload: highlighting good team work and supportive working environments. This model supported achievement of Standard 2 'Facing the Future' standards and was recognised in the NHSI cross county review of paediatric services.

Conclusion The qualitative and quantitative outcomes were presented to our Trust, A\&E delivery board and the STP business planning teams. The business case was successfully supported for funding a permanent PAU from January 2020. A PAU alongside ED remains the long term ambition for an integrated front door/acute paediatric assessment hub.

\section{G129(P) ISOTONIC MAINTENANCE IV FLUIDS IN INFANTS UNDER 3 MONTHS AS PER NICE GUIDANCE: A CLINICAL AUDIT}

WAJC Chandrakumara, R Furr, A Bunting, ASJ Marshall. Department of Paediatrics, Oxford University NHS FT, Oxford, UK

10.1136/archdischild-2020-rcpch.102

Aims

- Audit the type of IV fluid prescribed against NICE recommendations

- Monitor incidents of hypo- and hyper-natraemia

Methods Data were collected from the electronic patient record system (EPR). All fluid prescriptions and electrolyte tests were analysed during three data collection periods:

- First Audit Period, with promotion of local (NICE-based) guideline

- Second Period, before introduction of EPR IV fluid prescription 'power plan'

- Third Audit Period, after introduction of EPR power plan

We looked at EPR records of patients who had incidents of sodium abnormalities to determine whether they could have been iatrogenic.

Results A total of 568 fluid prescriptions were analysed. Data in the first audit cycle showed only $40 \%$ of fluid prescriptions were isotonic and the rest were hypotonic. Whilst on IV fluids, there were 12 patients with hyponatraemia, 11 of whom were on hypotonic fluids.

These findings were disseminated to general paediatric and paediatric surgical teams, and the local IV fluid guideline was promoted. On the EPR prescription system, a 'power plan' was introduced, which makes isotonic maintenance fluids the default option. 